\title{
Use of webQDA software on qualitative nursing research: an experience report
}

\author{
Uso do software webQDA na pesquisa qualitativa em enfermagem: relato de experiência \\ Uso del software webQDA en investigación cualitativa en enfermería: reporte de experiencia
}

Ana Larissa Gomes Machado' ORCID: 0000-0002-7937-6996

Neiva Francenely Cunha Vieira" ORCID: 0000-0002-9622-2462

'Universidade Federal do Piauí. Picos, Piauí, Brazil. "Universidade Federal do Ceará. Fortaleza, Ceará, Brazil.

How to cite this article:

Machado ALG, Vieira NFC. Use of webQDA software on qualitative nursing research: an experience report. Rev Bras Enferm. 2020;73(3):e20180411. doi: http://dx.doi.org/10.1590/0034-7167-2018-0411

Corresponding author:

Ana Larissa Gomes Machado Email: analarissa2001@yahoo.com.br

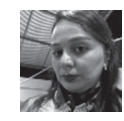

EDITOR IN CHIEF: Antonio José de Almeida Filho ASSOCIATE EDITOR: Andrea Bernardes

Submission: 06-08-2018 Approval: 04-29-2019

\begin{abstract}
Objectives: to report the user experience of the webQDA software in the support of qualitative data analysis about health literacy of older adults. Methods: quasi-experimental research developed from January 2014 to January 2015, with 118 older adults, all of whom were interviewed to assess the level of health literacy. Interviews were carried out before and after four educational interventions, according to Freire's method named Culture Circle. The interviews were transcribed and entered in the software, which highlighted the analytical categories. Results: the systems of sources, interpretative encoding and questioning of the data available in the software allowed the construction of three categories for the literacy levels and four categories for their dimensions. Final considerations: We concluded that the webQDA software enables the structured encoding of qualitative materials, ensuring faster and effective management of data with systematization and analytical transparency. Descriptors: Qualitative Research; Software; Nursing; Health literacy; Health of the Older Adult.
\end{abstract}

\section{RESUMO}

Objetivos: relatar a experiência de uso do software webQDA no apoio à análise dos dados qualitativos acerca do letramento em saúde de idosos. Métodos: pesquisa quase experimental desenvolvida no período de janeiro de 2014 a janeiro de 2015, com 118 idosos, os quais foram entrevistados para avaliar o nível de letramento em saúde. Foram realizadas entrevistas antes e após quatro intervenções educativas, segundo o método problematizador freireano denominado Círculo de Cultura. As entrevistas foram transcritas e inseridas no software, o que permitiu evidenciar as categorias analíticas. Resultados: os sistemas de fontes, codificação interpretativa e questionamento dos dados disponíveis no software permitiram a construção de três categorias para os níveis do letramento e de quatro categorias para as suas dimensões. Considerações finais: Conclui-se que o software webQDA permite a codificação estruturada dos materiais qualitativos, assegurando gestão mais rápida e eficaz dos dados a partir da sistematização e transparência analítica.

Descritores: Pesquisa Qualitativa; Software; Enfermagem; Alfabetização em Saúde; Saúde do Idoso.

\section{RESUMEN}

Objetivos: relatar la experiencia con la utilización del software webQDA como base al análisis de los datos cualitativos sobre literacidad en salud de ancianos. Métodos: investigación cuasiexperimental realizada en el período de enero de 2014 a enero de 2015, en la cual participaron 118 ancianos mediante entrevistas para evaluar el nivel de literacidad en salud. Se realizaron entrevistas antes y después de cuatro intervenciones educativas, de acuerdo con el método problematizador freireano titulado Círculo de Cultura. Se transcribieron las entrevistas y las insertaron en el software, lo que permitió obtener las categorías analíticas. Resultados: los sistemas de fuentes, de codificación interpretativa y de cuestionamiento de los datos disponibles en el software permitieron elaborar tres categorías sobre los niveles de literacidad y cuatro categorías sobre sus dimensiones. Consideraciones finales: Se concluyó que el software webQDA permite la codificación estructurada de los materiales cualitativos, lo que promueve una gestión más rápida y eficaz de los datos a partir de la sistematización y transparencia analítica.

Descriptores: Investigación Cualitativa; Programas Informáticos; Enfermería; Alfabetización en Salud; Salud del Anciano. 


\section{INTRODUCTION}

The qualitative approach has been excelling in research in nursing, since the nurses study relevant phenomena about the care of people, seeking to interpret the meanings they express about their experiences related to the health-disease process ${ }^{(1)}$. As a qualitative researcher, the nurse combines rigorous methodological procedures to understand the world of the participants, unveiling meanings, values and beliefs that emerge from the relationships among people and how they enjoy their experiences ${ }^{(2)}$.

Nursing plays a proactive and decisive role in the planning, implementation and evaluation of care, thus, the studies carried out by nurses have been contributing to redirect the ways of thinking and systematize the health care, to the extent the care appears as a healthy element of the praxis of the nurse and is in constant debate.

It is challenging, therefore, to organize and analyze the empirical material collected with the subjects of a survey conducted in situations of vulnerability or in which people need specific health care. Thus, the aim of this article is to report a quasi-experimental study, conducted with older hypertensive patients, based on the convergence between the educational practice and research practice of nurses using the webQDA software to support the qualitative data analysis.

The use of qualitative data analysis software is known in the literature as Qualitative Data Analysis Software (QDAS) and has expanded both in relation to users and to the number of applications/softwares available in the market. The incorporation of technological resources in the studies does not reduce the importance of the researcher in data interpretation and analysis, because the software help only with the organization and operation of the materials collected ${ }^{(3)}$.

These computational tools are especially useful with a qualitative research with a large volume of data or when it is necessary to cross information using the characteristics of the subjects of the study. In this study, we made more than one hundred interviews, which required a software to support the qualitative research with tools that facilitate data encoding, the reduction in the time of the analysis, the management of sources of information and knowledge construction with more depth and less subjective interference of the researchers.

Thus, the webQDA software was chosen to analyze the data mainly by the volume of interviews and by the need to cross results. The webQDA has advantages over other qualitative analysis software, such as its compatibility with various operating systems, the easy access to the project on any computer with internet and the availability of interactive tools and task sharing, providing the validation of processes and products, allowing other researchers to evaluate, partially or totally, coded categories and their content ${ }^{(4)}$.

Historically, the qualitative researcher faces several challenges for scientific recognition; however, qualitative studies have been consolidated from the use of tools that impart greater accuracy and systematization to them, such as the support for the webQDA qualitative analysis.

That way, the report presented here stresses the importance of this tool in the analysis of the qualitative data produced by nurses, considering the sharp growth in the integration of information and communication technologies in qualitative studies and their inevitable usability in the academic scenario. Considering the studies on nursing, the qualitative research requires a higher capacity of data management and methodological rigor, which are provided by the software used in this study.

This case study was developed to show the use of this methodological tool in a qualitative research conducted by nurses and presents how the webQDA software can be used to generate good and valid results, so other researchers meet the tool and use it as a support to their analysis, reducing the resistance of the use of these technological resources in order to analyze qualitative data.

In addition, this report shows how the use of software in qualitative research can help resolve the subjectivity of the researchers involved in the development of the study, in addition to improving the process of organization and data analysis. It should be noted that when conducting a study of this nature, the researcher will not examine only people's words, but also the non-verbal information, the emotions expressed by the participant and his/her gestures, not detectable by the informatics resources.

This study reports the user experience of webQDA as a tool to support the qualitative data analysis of a quasi-experimental research conducted in two basic health units (BHU) of the municipality of Picos-PI, in Northeast Brazil, with 118 older adults with hypertension, divided between Intervention Group (IG) and Control Group (CG).

The IG participated in four educational interventions using the methodology of Paulo Freire, named Culture Circle, which were held following the three steps proposed by the "Paulo Freire method"(5): thematic investigation, thematization and questioning. The average length of each meeting was 2 hours. The CG did not participate in the Culture Circle, but it was accompanied by the health team in the routine of hypertensive care in primary health care.

The outcome evaluated in the older adults was the level of health Literacy (HL). This theme is still new in the Brazilian literature, but as it is limited to the field of health education, it has been studied by researchers concerned with the empowerment of the older adults seen at the Unified Health System (SUS).

The term $\mathrm{HL}$ is polysemic and the essence of the definitions of the concept presented in the literature is represented here as the knowledge, motivation and skills to access, understand, evaluate and apply information, making judgments and decisions on a daily basis, with regard to health care, disease prevention, and health promotion, in order to maintain or improve the quality of life ${ }^{(6)}$.

In this study, the older adults were assessed at the HL level using an instrument prepared by Canadian researchers ${ }^{(7)}$ and validated for use in Brazil(8). This tool consists of structured and unstructured questions, it was applied to all participants in the investigation at two moments: at the beginning of the survey, before any educational activity, and at the end of the study.

The assessment of the $\mathrm{HL}$ level considered the dimensions of personal skills in using health information and making conscious decisions, namely: skills (reading, writing, counting, communication and search for health information), capabilities (sight, hearing, speech, memory, cognition), understanding of information, individual moderating factors (motivation, self-efficacy, attitude for results, social support and coping strategies) and results in health (adoption of favorable or unfavorable behaviors, participation in the health care plan and understanding their rights while users $)^{(9)}$.

This study adopted the classification of $\mathrm{HL}$ level proposed at the 7th Global Conference on Health Promotion: functional, conceptual, and empowerment ${ }^{(10)}$. It is noteworthy that the classifications 
adopted in this investigation have complied with the nature of the data collected for this analysis, which were predominantly qualitative.

\section{OBJECTIVES}

To report the user experience of the webQDA software in the support of qualitative data analysis about health literacy of older adults.

\section{THE USE OF THE WEBQDA SOFTWARE IN THE DATA ANALYSIS}

The data analysis conducted by the webQDA is similar to the basic structure of content analysis: a) pre-analysis, with the organization of the material to be analyzed; $b$ ) exploration of the material, with encoding and categorization; and c) treatment of the results, with the inferential interpretations.

The interviews with the older adults at the beginning and end of the study were transcribed and, later, skimming was conducted in order to highlight the nuclei of meaning associated with the empirical categories already detected: understanding the information about health, health system and social support. This analysis considered textual fragments that composed the corpus of research and whose presence or frequency of appearance brought meaning to the object of study. The results found with the empirical categories were confronted with the analytical categories previously delimited by the theoretical referential concerning the health literacy construct.

The amount of data collected and the need to discuss them with robustness required a software approach to support qualitative analysis, which provided the researcher more control over the material of analysis and more resources to answer the questions of the investigation.

It should be noted that this study was developed with a graduate program in nursing and, while the schedule of data collection of the research was being prepared, the researcher was trained to use the webQDA software, via participation in a training course held in 2014, in the city of Campinas, São Paulo.

The training enabled the use of the software, its features and advantages over the other programs available on the market in order to answer the questions of the study creatively and methodologically well founded. Furthermore, during the training, the researchers had the opportunity to develop a collaborative project that served as a learning base model of the functions available on the webQDA.

The webQDA is a software that has contributed to the accuracy and quality of the investigations. It does not require installation in the user's computer and its features allow editing, visualization and interconnection of documents in a collaborative environment and that works on the web, allowing the access and use of the tool simultaneously in more than one Internet point ${ }^{(4)}$.

Another advantage of the webQDA over other software to support the most used qualitative data analysis today is that none of them can be used by several researchers in a collaborative work environment and distributed based on the Internet, consisting in a huge gain in relation to its mobility. In its current version (3.0), the projects can be managed in mobile platforms (tablets and smartphones) with a more stable and friendly language $\mathrm{e}^{(4)}$.

Thus, both the data sources and the indexing system can be accessed online by all users that have been allowed access to the project. This service facilitates communication among researchers to edit and enter data in a specific project with the feature "project sharing," which allows the invitation of other users, such as advisors, to access, enter data, or just visualize the research data ${ }^{(4)}$.

The features of this tool are divided into three systems: I) sources, which correspond to the materials the researcher provides to be analyzed, such as interviews, videos or pictures; II) encoding, which allows for the definition of categories or indicators; III) questioning, which allows the researcher to question the data, based on the settings of the first two systems ${ }^{(4)}$.

\section{RESULTS}

The initial categories were built through the exhaustive reading of the interviews by researchers, considering the theoretical framework used in the investigation. Then the files with the transcription of the interviews were entered in the system of sources of the software, which also allows the addition of files in videos, image and audio formats.

The analysis of the interviews in the software started with the system of interpretative encoding tools, which provides features that enable the researcher to define open sources (agglutinating topics of ideas without hierarchical system or no connection between codes) and tree-codes (allow hierarchy in codes and subcodes according to the necessity and depth desired $)^{(4)}$. Using this encoding, the dimensions and the thematic areas were defined for classification of $\mathrm{HL}$ of older adults, which include textual fragments that highlight the nuclei of meaning associated with the empirical categories.

It is noteworthy that the encoding process of the text in the software is simple: just open the document (interview) that will be encoded, in the system of sources, and select the word or set of words that will designate the code. After this procedure, a reference column that shows the open sources created will appear, as well as the coded text snippets of the interviews.

To establish a hierarchical system to link the codes, tree-codes should be defined, which, similarly to the open sources, enable the visualization of text units coded in columns. The webQDA allows the user to move any code between the coding tools, for example, to move an "open source" to a "tree code."

The next step of the analysis was performed through the system of data questioning, consisting of the features: "most frequent words,"'text search,"'matrices" and "code search."This study used the feature "matrices" to formulate guiding questions such as: what is the relationship between the respondents' attitude and the levels of health literacy?

To structure a matrix in webQDA, the researcher needs to have full knowledge about the codes and subcodes elaborated, which can be challenging, as it requires effective communication on all data entered by each member of the staff, in case the project has been constructed collaboratively. Also, to interpret the results that will be generated, researchers must take ownership of the theoretical framework that supports the organization and definition of the lexical codes identified in the interviews.

From the operational point of view, the creation of matrices in the software involves the choice of codes that will be used in the rows and columns of the matrix and the definition of the relationship between the rows and columns selected ("AND" - intersection, "OR" - inclusion, "NO"- exclusion). It is also possible to restrict the search for documents 
on data sources by selecting part of them or including all files available (text, sound, image, video and audio) $)^{(4)}$.

The implementation of the webQDA software is a thorough process and requires the mastery of its features, but the execution of the actions is made in an intuitive virtual environment of easy handling. Computational tool features promote the organization of the materials attached to the source system and facilitate the encoding of the text of the interviews according to the theoretical framework used by the investigators.

The previous training conducted by researchers to use the software showed its suitability for the object of study and, through the readings of its features, it confirmed that its use in the research conducted by nurses is incipient. The scarcity of studies developed by these professionals with the application of webQDA showed the need to report the user experience of the software so that other researchers learn about this tool in order to have total mastery of its resources, which provide greater agility and robustness to the data analysis generated from the qualitative research.

It is noteworthy that the criteria the researchers used to select the webQDA as a tool to support the data analysis of this study were: its suitability for the type of investigation performed, availability in Portuguese language, and its features, enabling the work with different file formats, since the qualitative researcher deals with materials of varied origins, such as drawings, videos, audios and narrations.

Figure 1 shows the interpretative categorization of the HL levels performed with the support of the features of the software.

In Canadian ${ }^{(7)}$ and Brazilian ${ }^{(8)}$ studies that used the same tool to collect data about health literacy, results similar to those presented in this study were found regarding the content of the participants' responses. The tool used has several items with open questions, which resulted in large amount of material for analysis. The whole analytical process conducted with the support of the webQDA software in this study was facilitated by the systematic categorization available in the tool and, subsequently, by the possibility of crossing the results of different participants.

Figure 2, elaborated from the interpretative categorization with support of the software coding system, shows positive attitudes of self care that improve the health condition of older adults. It is valid to stress that to analyze the accounts of the older adults we considered two distinct periods: before and after their participation in Culture Circles.

After the participation of the older adults in the educational intervention, the contents of their accounts presented new terms that were identified in the software through the feature "most frequent words." The researchers did not have difficulty using this feature because the friendly software interface made the search for words easier.

We highlight the importance of the application of webQDA at the moment of analysis, because the analytical units or the textual fragments that would be encoded increased, requiring from the researchers a greater mastery of the tool to organize and encode the data. Without doubt, the analytical process was facilitated by the tool and did not cause any difficulties for the construction of the results presented here.

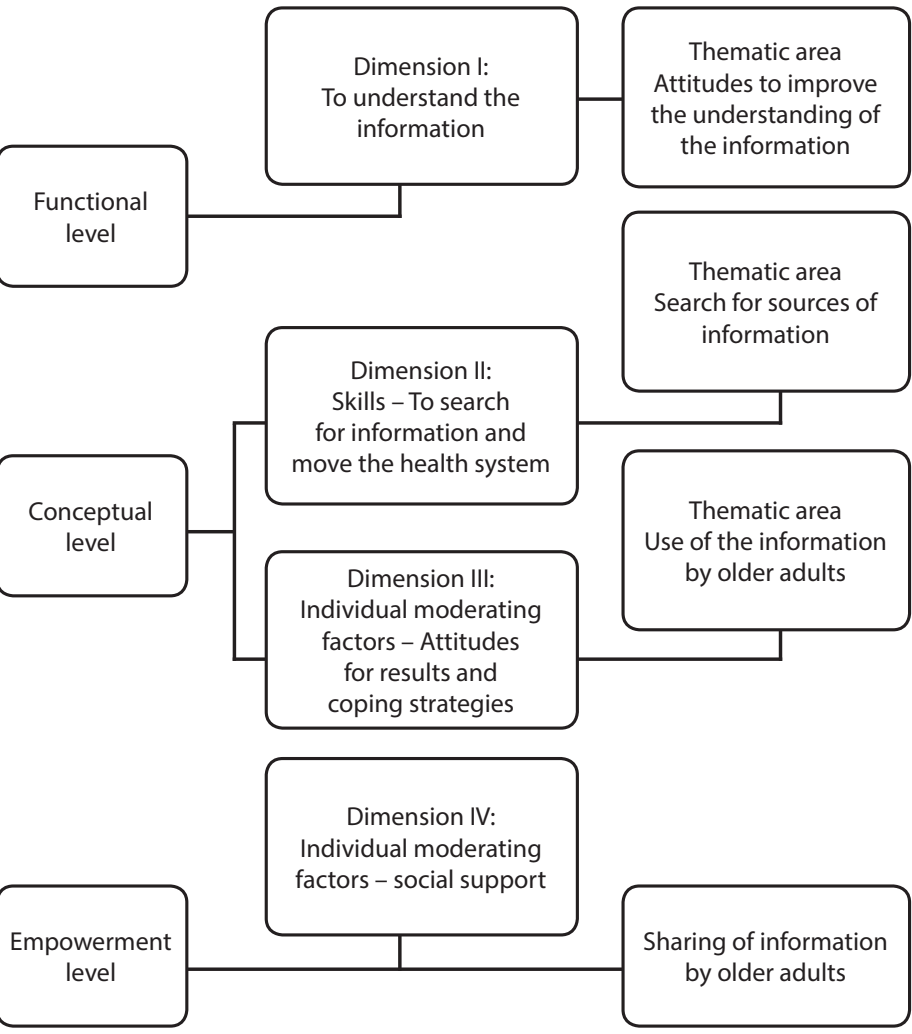

Figure 1 - Dimensions and thematic areas for classification of health literacy levels

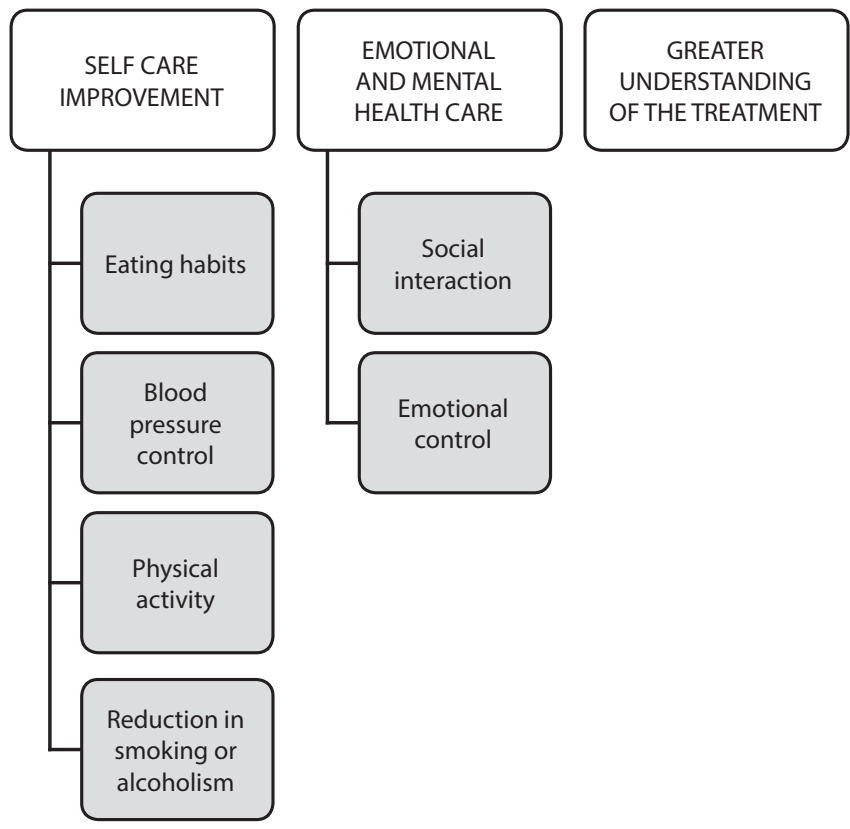

Figure $\mathbf{2}$ - Attitudes for results presented by the older adults

The insertion of the material in the webQDA enabled the verification of the density of data of interviews in the categories developed initially by researchers, leading to a reflection on the content of the tree of categories previously defined. After the categorization held with support of the software, some of the categories were restructured by the weak density of its content, being necessary to review the categories so that some 
subcategories were absorbed to consolidate the final tree of categories that defined the health literacy levels of older people.

Considering the nature of the data processed in this qualitative research, it is important to highlight the benefits arising from the use of the software as a tool that gives credibility to the research: a) analysis of a large amount of data in less time; b) definition of categories in an organized and transparent way;c) creative data analysis based on the systems of coding, recoding and questioning. The limitation of this study is the need for the investigator to have experience in computer resources and, especially, have some knowledge about the qualitative methods and the approach chosen to analyze the data.

\section{FINAL CONSIDERATIONS}

The results show that the webQDA software allows the structured encoding of qualitative materials with clarity in organization, interpretation and questioning, ensuring faster and effective data management with systematization and analytical transparency.
The data analysis with the support of the software qualifies the categorization and interpretation processes, assisting the inclusion or exclusion of empirical categories highlighted at the beginning of data organization by researchers, moment when the categories are listed from the thorough reading of the material and concepts relevant to the theoretical framework used in the research, which guided the whole analytical process conducted by the researcher with the support of the feature of the software.

Thus, we concluded that the use of software encourages the analytical process of the qualitative data from investigations conducted by nurses.

\section{FUNDING}

Conselho Nacional de Desenvolvimento Científico e Tecnológico (CNPq) for funding this research and Fundação de Amparo à Pesquisa do Estado do Piauí (Fapepi) for the doctoral scholarship that enabled the realization of part of this study.

\section{REFERENCES}

1. Cortes LF, Padoin SMM, Berbel NAN. Problematization methodology and convergent healthcare research: praxis proposal in research. Rev Bras Enferm [Internet]. 2018;71(2):440-5. doi: 10.1590/0034-7167-2016-0362

2. Minayo MCS. Qualitative analysis: theory, steps and reliability. Ciênc Saúde Colet. 2012;17(3):621-6. doi: 10.1590/S1413-81232012000300007

3. Costa AP, Faria BM, Reis LP. Investigação qualitativa através da utilização de software: workflows metodológicos. RISTI [Internet]. 2016 [cited 2018 May 10];(19):9-12. Available from: http://www.scielo.mec.pt/pdf/rist/n19/n19a01.pdf

4. Souza FN, Costa AP, Moreira A, Souza DN, Freitas F. webQDA: manual de utilização rápida [Internet]. Aveiro: UA Editora; 2016 [cited 2018 May 10]. Available from: https://app.webqda.net/Fontes/Manual_de_Utilizacao_webQDA.pdf

5. Freire P. Pedagogia do oprimido. 42nd ed. Rio de Janeiro: Paz e Terra; 2005.

6. Sørensen K, Broucke SV, Fullam J, Doyle G, Pelikan J, Slonska Z, et al. Health literacy and public health: a systematic review and integration of definitions and models. BMC Public Health. 2012;12(80):1-13. doi: 10.1186/1471-2458-12-80

7. Kwan B, Frankish J, Rootman I. The development and validation of measures of "health literacy" in different populations [Internet]. Vancouver: Institute of Health Promotion Research, University of British Columbia; 2006 [cited 2018 May 10]. Available from: http://blogs. ubc.ca/frankish/files/2010/12/HLit-final-report-2006-11-24.pdf

8. Paskulin LMG, Aires M, Valer DB, Morais EP, Freitas IBA. Adaptation of an instrument to measure health literacy of older people. Acta Paul Enferm. 2011;24(2):271-7. doi: 10.1590/S0103-21002011000200018

9. McCormack L. What is health literacy and how do we measure it? [Internet]. In: IOM Workshop on Measures of Health Literacy; 2009 Feb 26; Washington: 2009 [cited 2018 May 10]. Available from: http://www.nationalacademies.org/hmd/ /media/Files/Activity\%20Files/ PublicHealth/HealthLiteracy/McCormack.pdf

10. Kanj M, Mitic W. Health literacy and health promotion. Definitions, concepts and examples in the Eastern Mediterranean Region [Internet]. In: Proceedings of the 7th Global Conference on Health Promotion; 2009 Oct 26-30; Nairobi, Kenya. Geneva: World Health Organization; 2009 [cited 2018 May 10]. Available from: http://www.dors.it/documentazione/testo/201409/02_2009_OMS\%20Nairobi_Health\%20Literacy.pdf 